\title{
Sapphyrin-Nanotube Assemblies
}

Peter J. Boul, Dong-Gyu Cho, G. M. Aminur Rahman, Manuel Marquez, Zhongping Ou, Karl Kadish, Dirk M. Guldi, Jonathan, L. Sessler

\footnotetext{
Contribution from the University of Texas at Austin, Department of Chemistry and Biochemistry, 1 University Station A5300, Austin, TX. 78712, INEST Group Postgraduate Program, Philip Morris USA, Richmond, VA 23234, the Institute for Physical and Theoretical Chemistry, Friedrich-Alexander-Universität Erlangen-Nürnberg, 91058 Erlangen, Germany, Research Center, Philip Morris USA, 4201 Commerce Road, Richmond, VA 23234, and Department of Chemistry, University of Houston, Houston, TX 77204-5003. RECEIVED DATE (automatically inserted by publisher); sessler@mail.utexas.edu
}

\section{Supporting Information}

Figure S1. Transient absorption of nanotube sapphyrin assemblies..............Page S2

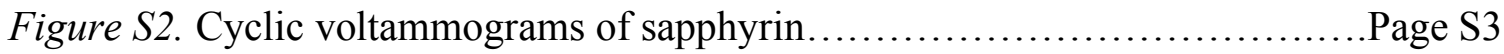

Figure S3. Differential absorption spectra recorded following pulsed radiolysis...Page S4

Figure S4. Differential absorption changes from pulsed radiolysis...............Page S5

Figure S5. Transient absorption of the sapphyrin-nanotube assembly.............Page S6 


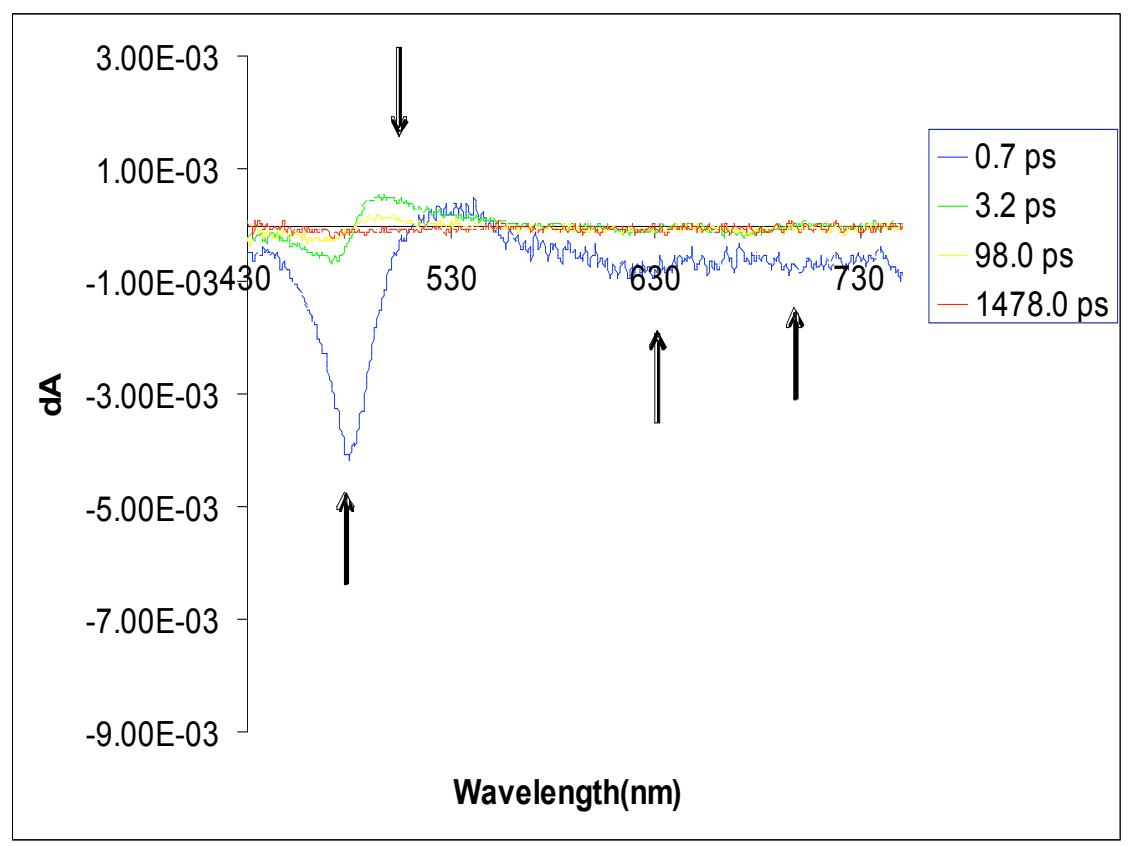

(a)

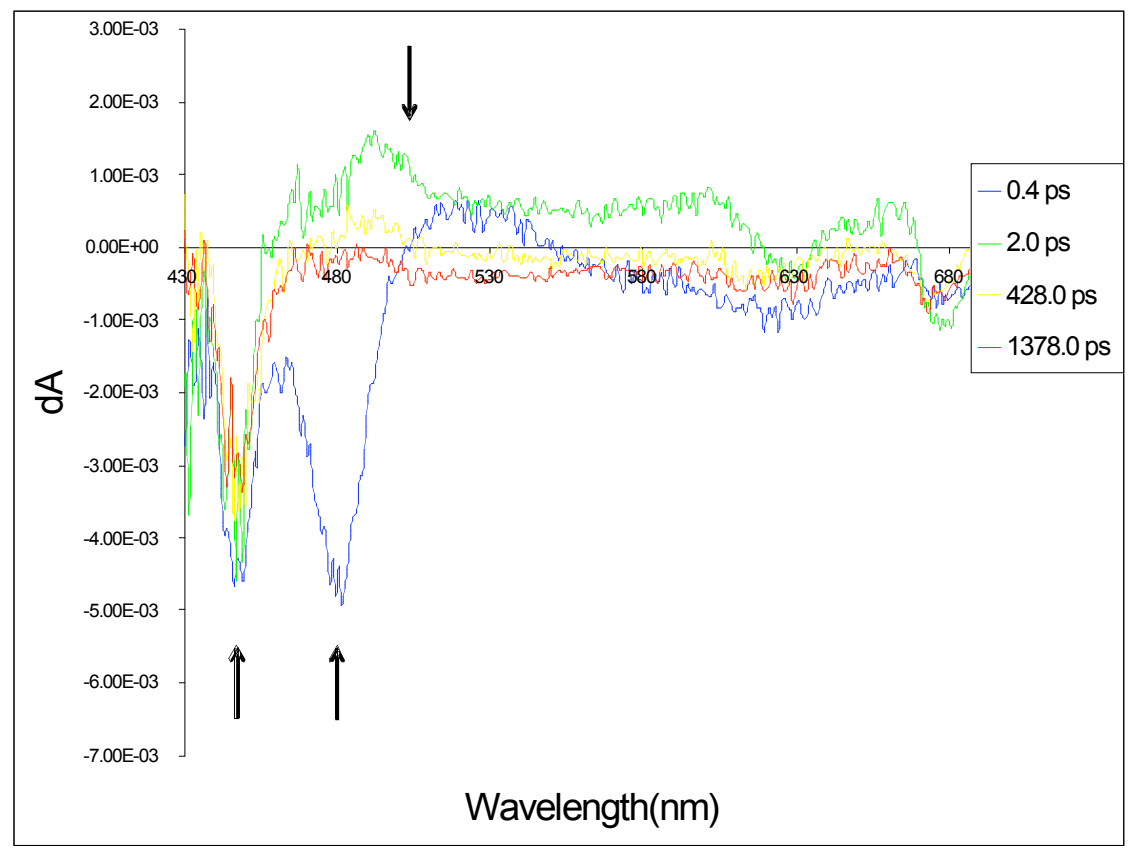

(b)

Figure S1. $387 \mathrm{~nm}$ flash photolysis transient absorption spectra of nanotube-sapphyrin complexes in (a) water and (b) BMIM-PF6. Note the bleaching of the Soret-like band at $481 \mathrm{~nm}$. 


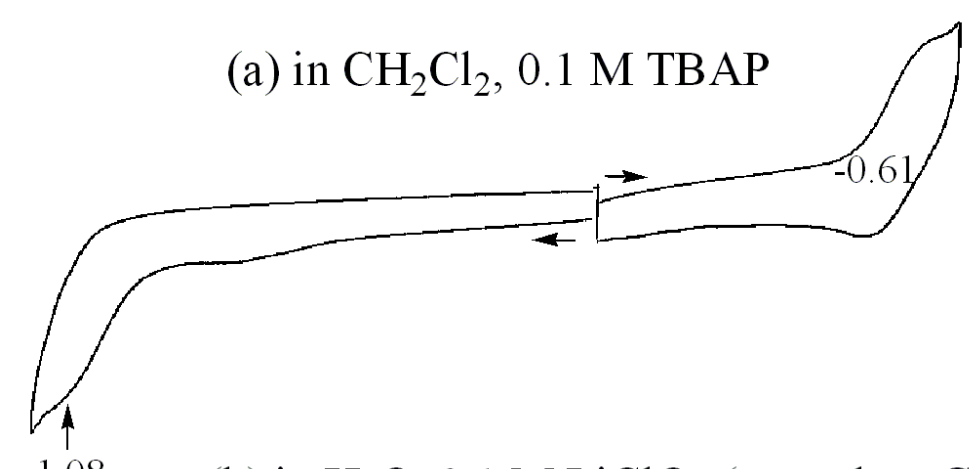

(b) in $\mathrm{H}_{2} \mathrm{O}, 0.1 \mathrm{M} \mathrm{LiClO}_{4}$ (coated on GCE)
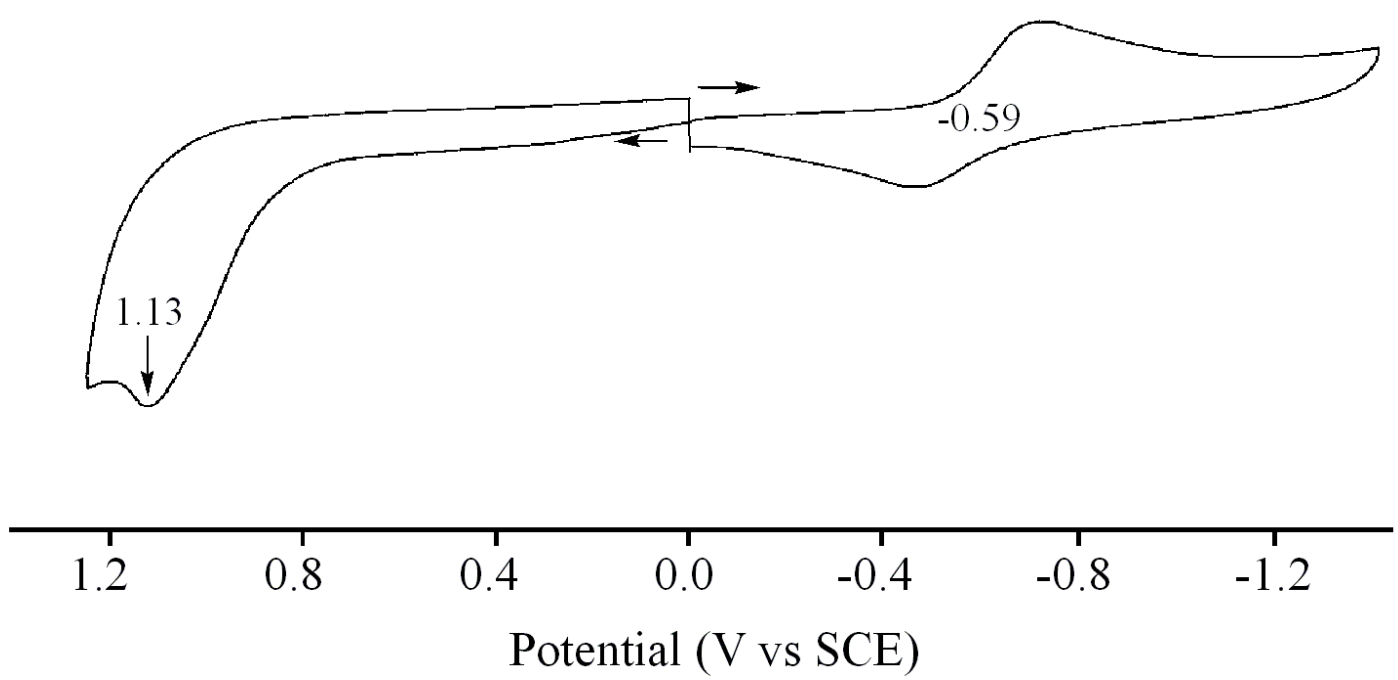

Figure S2. Cyclic voltammograms of sapphyrin (a) in $\mathrm{CH}_{2} \mathrm{Cl}_{2}, 0.1 \mathrm{M}$ TBAP and (b) coated on the surface of a glassy carbon electrode $(\mathrm{GCE})$ in $\mathrm{H}_{2} \mathrm{O}, 0.1 \mathrm{M} \mathrm{LiClO}_{4}$ (scan rate $=0.1 \mathrm{~V} / \mathrm{s}$ ). 


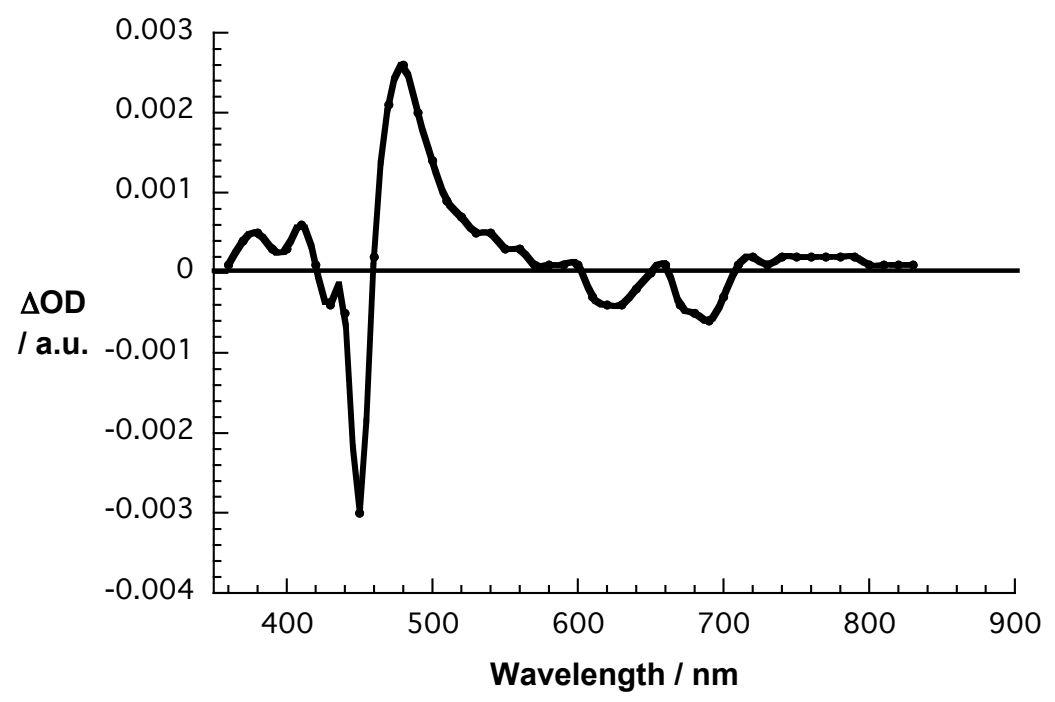

(a)

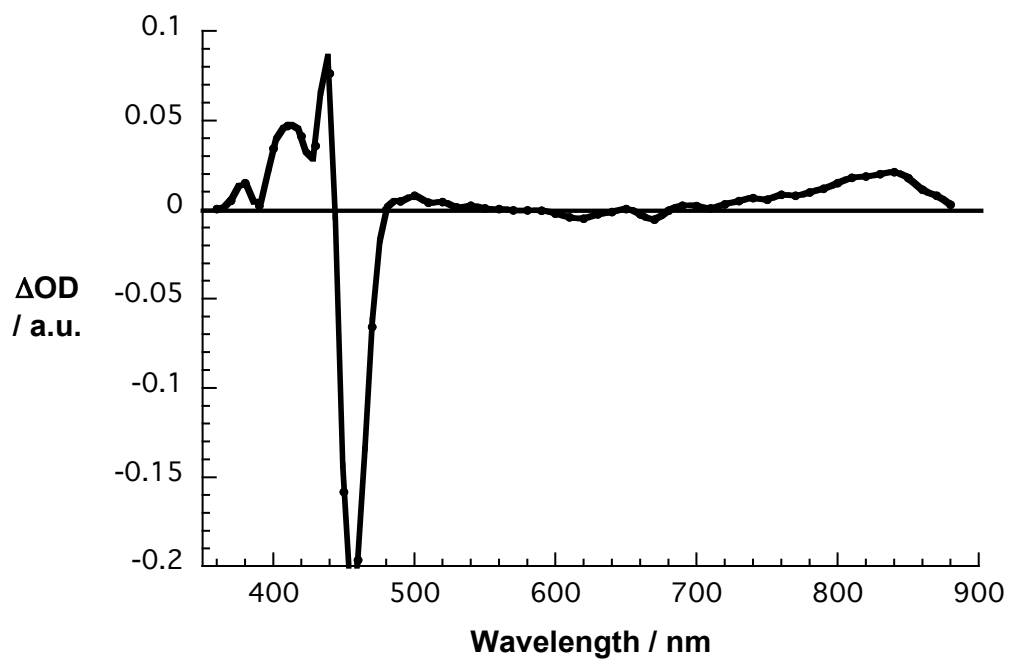

(b)

Figure S3. Differential absorption spectra recorded following (a) $200 \mu \mathrm{s}$ after pulse radiolytic oxidation of sapphyrin in oxygenated dichloromethane with ${ }^{\circ} \mathrm{OOCH}_{2} \mathrm{Cl}$ or - $O \mathrm{OCHCl}_{2}$ radicals and (b) $200 \mu \mathrm{s}$ after pulse radiolytic reduction of sapphyrin in deoxygenated 2-propanol with solvated electrons and $\left(\mathrm{CH}_{3}\right)_{2}{ }^{\circ} \mathrm{COH}$ radicals. 


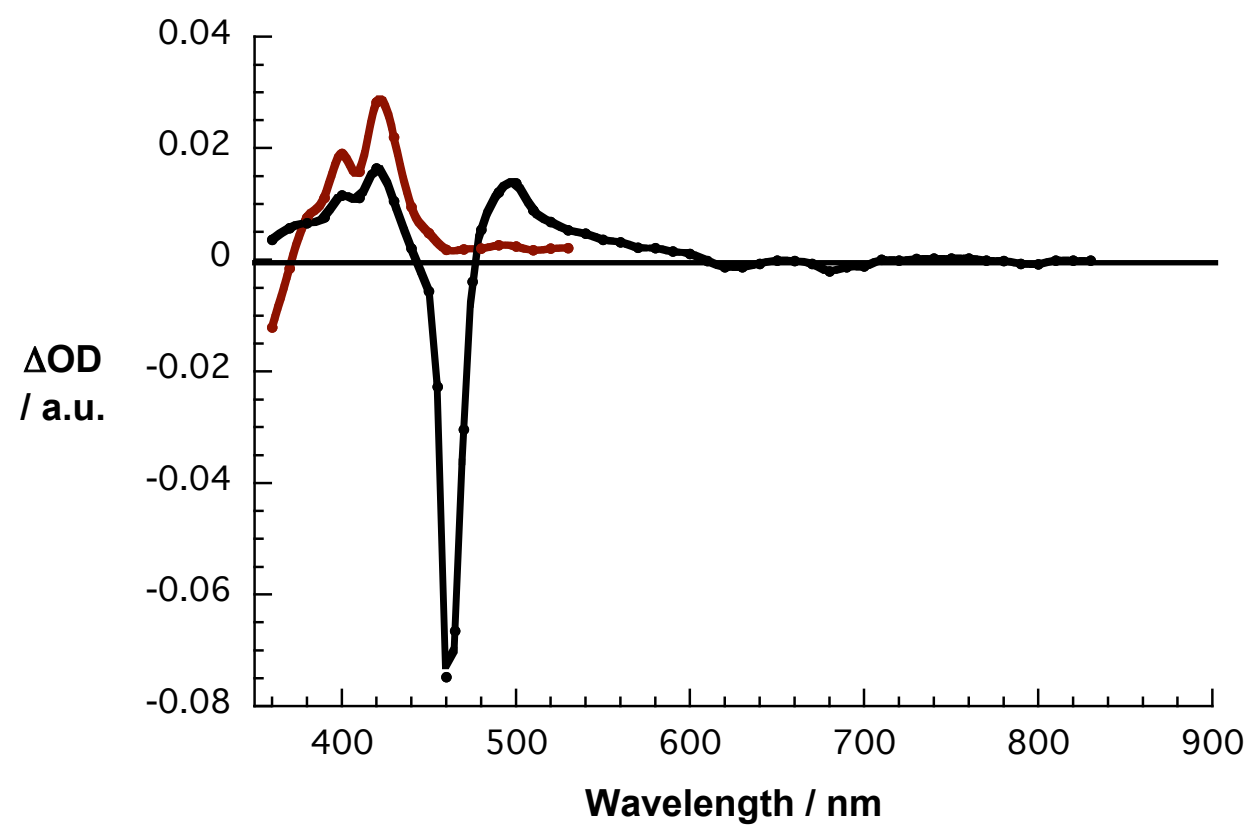

Figure S4. Differential absorption changes recorded $20 \mathrm{~ns}$ (red spectrum) and $200 \mu \mathrm{s}$ (black spectrum) after pulse radiolytic excitation of naphthalene $(0.02 \mathrm{M})$ and sapphyrin $\left(\sim 10^{-6} \mathrm{M}\right)$ in deoxygenated toluene. 


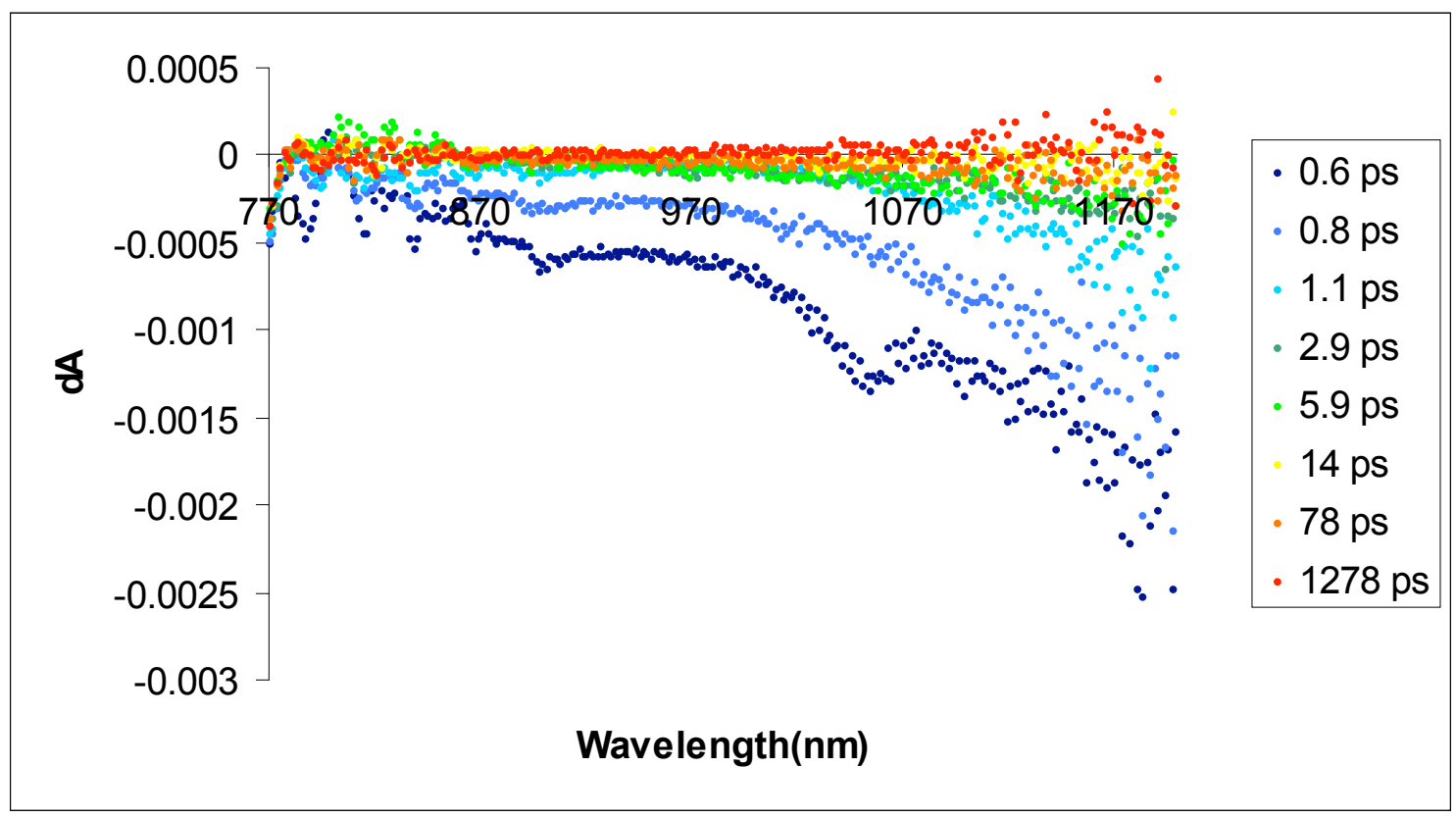

Figure S5. Femtosecond transient absorption spectrum of the sapphyrin-nanotube complex recorded after irradiation at $775 \mathrm{~nm}$, with monitoring being made in the near-IR spectral region. 